\title{
Inhibitory effect of mixture herbs/spices on formation of heterocyclic amines and
} mutagenic activity of grilled beef

Sepahpour, Shabnam; Selamat, Jinap; Khatib, Alfi; Manap, Mohd Yazid Abdul; Abdull Razis, Ahmad Faizal; Hajeb, Parvaneh

Published in:

Food Additives \& Contaminants: Part A - Chemistry, Analysis, Control, Exposure \& Risk Assessment

Link to article, DOI:

$10.1080 / 19440049.2018 .1488085$

Publication date:

2018

Document Version

Peer reviewed version

Link back to DTU Orbit

Citation $(A P A)$ :

Sepahpour, S., Selamat, J., Khatib, A., Manap, M. Y. A., Abdull Razis, A. F., \& Hajeb, P. (2018). Inhibitory effect of mixture herbs/spices on formation of heterocyclic amines and mutagenic activity of grilled beef. Food Additives \& Contaminants: Part A - Chemistry, Analysis, Control, Exposure \& Risk Assessment, 35(10), 1911. 1927. https://doi.org/10.1080/19440049.2018.1488085

\section{General rights}

Copyright and moral rights for the publications made accessible in the public portal are retained by the authors and/or other copyright owners and it is a condition of accessing publications that users recognise and abide by the legal requirements associated with these rights.

- Users may download and print one copy of any publication from the public portal for the purpose of private study or research.

- You may not further distribute the material or use it for any profit-making activity or commercial gain

- You may freely distribute the URL identifying the publication in the public portal 


\section{Inhibitory effect of mixture herbs/spices on formation of heterocyclic amines and mutagenic activity of grilled beef}

Shabnam Sepahpour, Jinap Selamat, Alfi Khatib, Mohd Yazid Abdul Manap \& Ahmad Faizal Abdull Razis

To cite this article: Shabnam Sepahpour, Jinap Selamat, Alfi Khatib, Mohd Yazid Abdul Manap \& Ahmad Faizal Abdull Razis (2018): Inhibitory effect of mixture herbs/spices on formation of heterocyclic amines and mutagenic activity of grilled beef, Food Additives \& Contaminants: Part A, DOI: $10.1080 / 19440049.2018 .1488085$

To link to this article: https://doi.org/10.1080/19440049.2018.1488085

Accepted author version posted online: 18

Jun 2018.

Submit your article to this journal $₫$

Q View related articles ¿

View Crossmark data 
Publisher: Taylor \& Francis

Journal: Food Additives \& Contaminants: Part A

DOI: $10.1080 / 19440049.2018 .1488085$

\title{
Inhibitory effect of mixture herbs/spices on formation of heterocyclic amines and
}

\section{mutagenic activity of grilled beef}

Shabnam Sepahpour ${ }^{\mathrm{a}}$, Jinap, Selamat ${ }^{\text {ab* }}$, Mohd Yazid Abdul Manap ${ }^{\mathrm{c}}$, Khatib Alfi ${ }^{\mathrm{d}}$, Ahmad Faizal Abdull Razis

${ }^{\mathrm{a}}$ Department of Food Science, Faculty of Food Science and Technology, Universiti Putra Malaysia, 43400

Serdang, Selangor, Malaysia; ${ }^{\mathrm{b}}$ Food Safety and Food Integrity (FOSFI), Institute of Tropical Agriculture and

Food Security, Universiti Putra Malaysia, 43400 Serdang, Selangor, Malaysia; ${ }^{\mathrm{c}}$ Department of Food

Technology, Faculty of Food Science and Technology, Universiti Putra Malaysia, 43400 Serdang, Selangor, Malaysia; ${ }^{\mathrm{d} D e p a r t m e n t}$ of Pharmaceutical Chemistry, Faculty of Pharmacy, International Islamic Universiti Malaysia. 25200 Kuantan, Pahang, Malaysia; ${ }^{\mathrm{e} H a l a l}$ Products Research Institute, Universiti Putra Malaysia, 43400 Serdang, Selangor, Malaysia

*Corresponding Author: Jinap, S. (sjinap@gmail.com; jinap@upm.edu.my)

\begin{abstract}
Natural antioxidants in spices and herbs have attracted considerable attention as potential inhibitors against the formation of mutagenic heterocyclic amines (HCAs) in heat processed meat. In this study, the inhibitory activity of four spices/herbs and their mixtures on HCAs formation in grilled beef were examined. A simplex centroid mixture design with four components comprising turmeric, curry leaf, torch ginger and lemon grass in 19 different proportions were applied on beef samples before grilling at $240{ }^{\circ} \mathrm{C}$ for $10 \mathrm{~min}$. HCAs were extracted from the samples using solid phase extraction (SPE) method and analyzed using LC-MS/MS. All
\end{abstract}


spices/herbs in single or mixture forms were found to reduce total HCAs concentrations in marinated grilled beef ranging from $21.2 \%$ for beef marinated with curry leaf to $94.7 \%$ for the combination of turmeric and lemon grass $(50: 50 \mathrm{w} / \mathrm{w})$. At the optimum marinade formula (turmeric: lemon grass $52.4 \%: 47.6 \%$ ), concentration of 2-amino-3-methylimidazo[4,5-f]quinolone (IQ), 2-amino-1-methyl-6-phenylimidazo[4,5-b]pyridine (PhIP), Harman, Norharman, and $\mathrm{A} \alpha \mathrm{C}$ were $2.2,1.4,0.5,2.8$, and $1.2 \mathrm{ng} / \mathrm{g}$, respectively. The results of the mutagenic activity demonstrated that this optimized marinade formula significantly $(\mathrm{p}<0.05)$ diminished mutagenicity of marinated grilled beef in bacterial Ames test.

Keywords: Heterocyclic amines; Marinated grilled beef; Herbs/Spices; Antioxidant activity; Mutagenicity

\section{Introduction}

Heterocyclic amines (HCAs) and polycyclic aromatic amines (PAH) are potentially mutagenic and carcinogenic compounds formed in meat products (beef, chicken and fish) during heat processing (frying, broiling, roasting, grilling and barbequing) at high temperatures over $150^{\circ} \mathrm{C}$ (Szterk et al. 2015, Alaejos et al. 2008; Gibis and Weiss 2012; Oz et al. 2010).

Reducing sugar such as glucose, free amino acids and creatine are the precursors responsible for HCAs formation (Puangsombat et al. 2012). Although they are formed at parts-per-billion (ppb) level of concentration, several epidemiological experiments on cancer demonstrated that high consumption of cooked meat products increased the risk of cancer due to HCAs-DNA adduct formation which is postulated to be a biomarker of cancer risk (Zheng and Lee 2009). Numerous research findings have demonstrated that HCAs can cause alteration in DNA, such as breaking of the hydrogen bonds of the DNA chain, site mutation, insertion and deletion (Szterk 2015). The International Agency for Research on Cancer (IARC) classified HCAs as a probable human carcinogens (2-amino-3methylimidazo[4,5-f] quinoline (IQ) (class 2A) and possible human carcinogens (class 2B) (2-amino-1- methyl-6phenylimidazo[4,5-b]pyridine (PhIP), (2-amino-3,4-dimethyl-imidazo[4,5-f]quinoline (MeIQ), and 2-amino- 3,8dimethyl-imidazo[4,5-f]quinoxaline (MeIQx) (Szterk 2012, Gibis, et al. 2015). 
HCAs are divided into two main groups named amino imidazo-azaarenes (IAAs) and amino-carbolines (ACs) based on the temperature and pathway of the formation (Murkovic 2004). Amino imidazo-azaarenes known as polar HCAs are the most important class of HCAs in meat cooked at temperature above $150{ }^{\circ} \mathrm{C}$. It is believed that formation of polar HCAs initiates with Maillard reaction between reducing sugars especially glucose and different free amino acids (Gibis and Weiss, 2010; Puangsombat et al. 2012; Yu et al. 2016) and terminated by condensation of creatinine with pyridine and pyrazine free radicals intermediates of Maillard reaction. Pyrolysis of free amino acids, such as phenylalanine, glutamic acid, tryptophan, lysine and ornithine create amino-carbolines or non-polar HCAs such as Phe-P-1, Glu-P-1, Trp-P-1 and Lys-P-1 and Orn-P-1. It also has been reported that some proteins, as such soy albumin, globulin, casein and gluten at the temperatures above $250{ }^{\circ} \mathrm{C}$ were produced HCAs; however, the mechanism has not been fully elucidated (Kizil et al. 2011).

In the past years, numerous studies were performed to develop some strategies which could beneficially reduce or inhibit HCAs formation in real meat matrix or in chemical model systems. Reducing cooking temperature and time (Oz et al., 2010), lower storage of meat (Szterk 2015), using fatty meat rather than lean meat (Szterk and Waszkiewicz-Robak 2014) microwave pretreatment of meat (Jinap et al., 2013) and marinating meat with different herbs and spices (Damašius, Venskutonis, Ferracane, \& Fogliano, 2011; Gibis and Weiss, 2012) are the ways which were suggested to minimize HCAs formation in meat. Spices and herbs, which are rich in antioxidants, are promising materials for inhibition of HCAs formation in meat products due to their ability in scavenging free radicals (Oz and Kaya 2011; Gibis and Weiss 2010; Ahn and Grün 2005). Several researchers have reported that using black pepper powder (Oz and Kaya, 2011), extracts of basil, oregano, marjoram, rosemary, savory, thyme and coriander (Damašius, Venskutonis, Ferracane, and Fogliano, 2011), hibiscus (Gibis and Weiss 2010), and rosemary (Ahn and Grün 2005) as marinade ingredients could diminish HCAs concentrations in heat-processed meat products. Their ability in suppression of HCAs formation have been attributed to scavenging of free radicals formed during HCAs formation pathways (Puangsombat et al. 2011). 
Turmeric (Curcuma longa), curry leaf (Murraya koenegii), torch ginger (Etlingera elatior) and lemon grass (Cymbopogon citratus) are Asian spices and herbs widely used for flavoring and coloring in the preparation of different Asian cuisines (Wijekoon et al. 2011; Maheshwari et al. 2006; Singh et al. 2011; Figueirinha et al. 2008). Their antioxidant properties were reported by many researchers; thus, it is highly possible that they also will have inhibitory effects on HCAs formation in heat processed meat products. Among these herbs/spices, only inhibitory effect of turmeric was investigated on HCAs formation in fried beef (Puangsombat et al. 2011), and there is no information regarding mitigation of HCAs with curry leaf, lemon grass, and torch ginger and their combinations in heat-processed meat. This study was conducted to determine the effects of individual and combination of selected herbs/spices in different proportions on reduction of HCAs in grilled beef. For this purpose, a mixture design of experiment (simplex centroid design) was performed with four spices/herbs as the ingredients in marinade formula.

\section{Material and methods}

\section{Chemicals and reagents}

All HCAs standards, 2-amino-3-methyl-3H-imidazo[4,5-f]quinoxaline (IQx), 2-amino-3-methylimidazo[4,5f]quinoline (IQ), 2-amino-3,8-dimethyl-imidazo[4,5-f]quinoxaline (MeIQx), 2-amino-3,4 dimethylimidazo[4,5f]quinoline (MeIQ), 2-amino-3,4,8- trimethylimidazo[4,5-f]quinoxaline (7,8-DiMeIQx), (PhIP), 2-Amino3,4,7,8-tetramethyl-3H-imidazo[4,5-f]quinoxaline (4,7,8-TriMeIQx), 2-Amino-9H-pyrido[2,3-b]indole (A $\alpha$ C), Harman, and Norharman were bought from Toronto Research Chemicals (Toronto, Canada). All HCAs standards were in powdered form with $99 \%$ purity and dissolved in methanol to give stock solution of $100 \mu \mathrm{g} / \mathrm{mL}$. For the recovery of HCAs, diatomaceous earth from the International Sorbent Technology (Hengoed Mid Gleam, UK) and Oasis MCX cartridges $\left(3 \mathrm{~cm}^{3} / 60 \mathrm{mg}\right.$ ) from Waters (Milford, MA, USA) were used. All phenolic standards including curcumin, demethoxycurcumin, bisdemethoxycurcumin, rutin, quercetin3-glycoside, myrecitin, quercetin, chlorogenic acid, caffeic acid, p-coumaric acid, luteolin-7-o-glycoside were 
purchased from Sigma-Aldrich (St. Louis, USA). For antioxidant activity analysis, 1,1-diphenyl-2picrylhydrazyl (DPPH), ferric chloride, potassium ferricyanide, and trichloroacetic acid (TCA) and all analytical grade of organic solvents for extraction of HCAs, HPLC grade solvents for detection of HCAs were obtained from Merck. (Darmstadt, Germany). Creatine Colorimetric/Fluorometric Assay kit was purchased from BioVision Inc. (Milpitas, CA, USA). Dimethyl sulfoxide (DMSO), benzo[a]pyrene and histidine-biotin solution were bought from Sigma-Aldrich (St. Louis, MO, USA).

\section{Preparation of marinating ingredients}

All herbs and spices, turmeric (Curcuma longa), curry leaf (Murraya koenegii), torch ginger (Etlingera elatior) and lemon grass (Cymbopogon citratus), were purchased freshly from a local-market in Selangor, Malaysia; cleaned and washed thoroughly under running tap water. The excess water was drained. They were chopped into small pieces and freeze-dried. Then, they were grounded into fine powder using a mechanical kitchen blender (Model DPA1, Tefal, Rumilly, France) and sieved (Woven wire mesh, Endecotts, London, England) to obtain particle size less than $630 \mu \mathrm{m}$; kept in prepared polyethylene (PE) containers and stored at $-20^{\circ} \mathrm{C}$ prior to extraction and marinating.

\section{Extraction of herbs and spices}

The freeze-dried samples were extracted in $80 \%(\mathrm{w} / \mathrm{v})$ ethanol for 1 hour using magnetic stirrer. The ratio of sample to solvent was $1: 10(\mathrm{w} / \mathrm{v})$. The extracts were filtered through Whatman No.1 filter paper (Whatman International Ltd. Maidston, England) and concentrated using a vacuum rotary evaporator (Buchi, Rotavapor R210, Flawil, Switzerland) under low pressure. The residue was freeze-dried, and then kept at $-18^{\circ} \mathrm{C}$ prior to further analysis.

\section{Determination of antioxidant activity of herbs and spices used in marinades}


FRAP was determined according to the modified method described by Shon et al. (2003). In this method, antioxidants reduce the ferric ion $\left(\mathrm{Fe}^{3+}\right)$ to ferrous ion $\left(\mathrm{Fe}^{2+}\right)$, a blue product, which has maximum absorption at $700 \mathrm{~nm}$. An aliquot $(1 \mathrm{~mL})$ of methanolic extract solution was diluted in $2.5 \mathrm{~mL}$ of $20 \mathrm{M}$ phosphate buffer $(\mathrm{pH}$ : 6.6) and $2.5 \mathrm{~mL} 1 \%(\mathrm{w} / \mathrm{v})$ potassium ferricyanide, followed by incubating the mixture at $50^{\circ} \mathrm{C}$ for $30 \mathrm{~min}$. After incubation, $2.5 \mathrm{~mL}$ of trichloroacetic acid (10\%) was added to the solution and centrifuged (Sigma 3-18K, Sartorius, Gettingen, Germany) at $650 \mathrm{~g}$ for $10 \mathrm{~min}$. The supernatant (5 mL) was taken and mixed with distilled water $(5 \mathrm{~mL})$ followed by $500 \mu \mathrm{L}$ ferric chloride solution $(1 \% \mathrm{w} / \mathrm{v})$ and mixed thoroughly. Solution was incubated at ambient temperature for $10 \mathrm{~min}$. The absorbance was recorded at $700 \mathrm{~nm}$ using Genesys $10-\mathrm{S}$ UVVis spectrophotometer (Thermo Fisher Scientific,Waltham, MA, USA) and expressed as milligram quercetin equivalent/g freeze-dried of crude extract (mg QE/g CE).

\section{DPPH free radical-scavenging assay}

The antioxidant capacity of the extracts was measured following the method described by Álvarez-Casas et al. (2014) using DPPH radical scavenging assay. An aliquot $(100 \mu \mathrm{L})$ of extracts $(0.8 \mathrm{mg} / \mathrm{mL})$ was mixed with 3.9 $\mathrm{mL}$ of $0.1 \mathrm{mM}$ methanolic DPPH solution. The mixture was thoroughly mixed and allowed to stand in the dark for $30 \mathrm{~min}$ at room temperature. The absorbance of solution was read at $517 \mathrm{~nm}$. Results were expressed as percentage of inhibition of the DPPH radical which was calculated according to the following equation:

(Eq. 1) $\%$ inhibition $=\frac{\text { A control }- \text { A sample }}{\text { A control }} \times 100$

where A control is the absorbance of the DPPH without plant extracts, and A sample is the absorbance of the DPPH after adding extracts.

\section{Identification and quantification of some bioactive compounds}


HPLC separation system was applied to determine the amount of some targeted phenolic content of each extract. An Aliquot of $(20 \mu \mathrm{l})$ the extracts were injected to Waters 600 HPLC system (Milford, Massachusetts, USA) with a UV-diode array detector system equipped by Hypersil Gold column C18 (5 $\mu \mathrm{m}, 250 \mathrm{x} 4.6 \mathrm{~mm}$, Thermo Fisher Scientific, Waltham, MA, USA). Various gradient programs were performed for different samples to achieve the optimum efficiency of chromatographic separation for each extract.

The quantification of turmeric active compounds including curcumin, desmethoxycurcumin and bisdesmethoxycurcumin was carried out using an isocratic method described by Wichitnithad et al. (2009) with slight following modification. Isocratic acetonitrile, $2 \%$ acetic acid 40:60 at $1 \mathrm{~mL} / \mathrm{min}$ of flow rate for $30 \mathrm{~min}$ was used with detection of flavonoids at $425 \mathrm{~nm}$. The column temperature was set at $33^{\circ} \mathrm{C}$.

For torch ginger and lemon grass, the same mobile phases, A: $0.2 \%$ aqueous formic acid and B: methanol with different gradients at a flow rate of $0.8 \mathrm{~mL} / \mathrm{min}$ were used to identify chlorogenic acid in torch ginger and in lemon grass caffeic acid, p-coumaric acid and luteolin-7-o-glycoside. Column temperature was set at $24^{\circ} \mathrm{C}$. The gradient HPLC for lemon grass described by Figueirinha et al. (2008) started with 95-85\% A (0-10 min), 8570\% A (10-15 min), 70-65\% B (15-25 min), 65-50\% A (25-35 min), 50-20\% A (35-40 min), followed by isocratic $20 \%$ A for $20 \mathrm{~min}$. Chromatographic profiles were acquired in the wavelength $280 \mathrm{~nm}$. For torch ginger, modified gradient was used: $75-60 \%$ A (0-15 min), 60-80\% A (15-25 min), 80-90\% A (25-30 min), 90-75\% A (30-40 $\mathrm{min})$. The compound was monitored at $265 \mathrm{~nm}$. A gradient chromatographic separation was performed (Singh et al. 2011) in order to determine the curry leaf bioactive compounds including rutin, Quercetin-3-glycoside, Myrecitin and quercetin at ambient temperature using a mobile phase of solvent A: 10\% methanol at $\mathrm{pH} 3.5$ with $0.01 \%$ formic acid and solvent $\mathrm{B}$ : methanol, water, acetonitrile (20:20:60) at $\mathrm{pH} 3.5$ with $0.01 \%$ formic acid, with a constant flow rate of $1 \mathrm{~mL} / \mathrm{min}$, ambient temperature for column and a detection wavelength of 366nm. The gradient program was:0-5 min 100\% A, 5-10 min $85 \%$ A, 10-20 min 80\% A, 20-25 
$\min 75 \%$ A, $25-27 \min 73 \%$ A, $27-30 \min 60 \%$ A, 30-35 min 50\% A, A: $35-40 \min 10 \%$ A, and returned to $100 \%$ A for $20 \mathrm{~min}$.

\section{Determination of precursor of HCAs in beef and marinade components}

\section{Glucose}

The sugar contents of beef, herbs, and spices were determined using HPLC equipped with refractive index detector (RI-1350, JASCO Corp. Tokyo, Japan). The column was NH2 polar bonded-phase (Agilent $250 \mathrm{~mm}$ $4.6 \mathrm{~mm}$ I.D.). Sugar standard was prepared in the concentrations range of $0.5-2 \%$ (w/y). Sugar extraction of beef samples was carried out prior to determination by HPLC using the method described by Hasnol, Jinap, and Sanny (2014) with some modifications. An aliquot $(10 \mathrm{~mL})$ of $75 \%$ acetonitrile was added to $10 \mathrm{~g}$ of the grounded beef and $1 \mathrm{~g}$ of herbs and spices, then the samples were centrifuged for $10 \mathrm{~min}$ at $700 \mathrm{~g}$. An aliquot (2 $\mathrm{mL}$ ) of aqueous phase was taken and filtered through $0.45 \mu \mathrm{m}$ nylon syringe filter (Macherey-Nagel, Düren, Germany), and a $20 \mu \mathrm{L}$ aliquot of the sample was injected to HPLC. The isocratic method was applied for 15 min. Mobile phase was acetonitrile-water $(80: 20, \mathrm{v} / \mathrm{v})$ with the flow rate of $1 \mathrm{~mL} / \mathrm{min}$.

\section{Extraction and determination of free amino acids}

Total free amino acids were determined using the Phenomenex EZ:faast ${ }^{\mathrm{TM}}$ amino acid analysis kit (Phenomenex, Torrance, CA, USA) (Badawy, Morgan, and Turner, 2008). An aliquot of (1 g) of beef, herb/spice samples were placed into three different $15 \mathrm{~mL}$ centrifuge tubes and $10 \mathrm{~mL}$ of acetonitrile $(50 \%)$ and $0.01 \mathrm{~N} \mathrm{HCl}$ was added to them to disrupt the cell wall and release the biological molecule within solution. Acetonitrile also was reported as an efficient solvent for precipitating the proteins of the sample (Polson et al. 2003). The prepared suspension was vortexed (IKA Vortex Genius3; IKA Werke GmbH and Co. KG, Staufen, Germany) vigorously for $3 \mathrm{~min}$ and centrifuged for $30 \mathrm{~min}$ at $700 \mathrm{~g}$ to remove the residue. An aliquot $(100 \mu \mathrm{L})$ of the supernatant 
was filtered through $0.45 \mu \mathrm{m}$ nylon syringe filter (Macherey-Nagel, Düren, Germany) and subjected to derivatization procedure using reagents that were provided in the Phenomenex EZ:faast ${ }^{\mathrm{TM}}$ amino acid analysis kit (Phenomenex, Torrance, CA, USA). Amino acids were quantified using Agilent 7890A GC-FID (Agilent Technologies, Wilmington, DE, USA). The column was a Zebron ZB-AAA capillary GC column $(10 \mathrm{~m} \times 0.25$ mm i.d., Phenomenex, Torrance, CA, USA). The column oven temperature program was as follow: 110 to $320^{\circ} \mathrm{C}$ at $32^{\circ} \mathrm{C} / \mathrm{min}$. The temperature of FID detector was $320^{\circ} \mathrm{C}$, and $1 \mu \mathrm{L}$ of each sample was injected at an injection temperature of $250^{\circ} \mathrm{C}$ and a split level of $1: 15$. The carrier gas was helium at a pressure of $3 \mathrm{kPa} / \mathrm{min}$ (a flow rate of $1.5 \mathrm{~mL} / \mathrm{min}$ ).

\section{Determination of creatine content}

Briefly, $5 \mathrm{~g}$ of sample were homogenized with $10 \mathrm{~mL}$ of $0.01 \mathrm{~N} \mathrm{HCl}$ for 15 min by vertical shaker and further centrifuged $11000 \mathrm{~g}$ for $20 \mathrm{~min}$ (Del Campo et al., 1998). An aliquot ( $2 \mu \mathrm{L}$ ) of the supernatant was subjected to Creatine Colorimetric/Fluorometric Assay kit (BioVision Inc., Milpitas, CA) according to the manufacturer's instructions.

\section{Determination of fat content of beef}

Fat content of raw beef was measured using the method described by Carpenter (2014) for meat samples in 960.39 of AOAC. Three grams of fresh sample was added to an extraction thimble. Petroleum ether (350 ml) was utilized for solving the fat content of the samples. Extraction was carried out for 3 samples at the same time for 6 hours. The amount of fat content was calculated from the difference between the weight of pre-dried boiling flask before and after extraction.

\section{Preparation of marinade and grilling condition of beef}


Fresh beef, fat content $12.4 \%$, was purchased and stored at $-20^{\circ} \mathrm{C}$ prior to marinating. One day before experiment, the frozen beef was thawed at $4^{\circ} \mathrm{C}$ overnight and then cut into small cubes $(2 \mathrm{~cm} \times 2 \mathrm{~cm}$ dimension). Herbs and spices (single or combination) were weighed (total $3 \mathrm{~g} / 100 \mathrm{~g}$ beef) for marinating of beef based on formula shown in Table 1 . The marinated beef cubes were kept in polyethylene bags at $4^{\circ} \mathrm{C}$ for eight hours and then skewered. They were grilled in electrical grilling $240^{\circ} \mathrm{C}$ for $10 \mathrm{~min}$.

\section{Extraction of heterocyclic amines}

Extraction and clean up procedures were carried out based on the method described by Hasnol et al. (2014). Exact weight, $5 \mathrm{~g}$ of each grilled beef samples was dissolved in $20 \mathrm{~mL}$ of $1 \mathrm{MNaOH}$ solution. The suspension was homogenized for 3 hours by means of a magnetic stirrer. The samples were mixed with $17 \mathrm{~g}$ diatomaceous earth and placed in Extrelut column $(20 \mathrm{~mL})$. A volume of $50 \mathrm{~mL}$ ethyl acetate was collected when it was utilized as extraction solvent. An aliquot $(25 \mathrm{~mL})$ of collected sample was passed through MCX column which was preconditioned with $2 \mathrm{~mL} 0.1 \mathrm{M} \mathrm{HCl}$ followed by $2 \mathrm{~mL}$ methanol. The column was eluted with $2 \mathrm{~mL}$ methanol:concentrated ammonia $(25 \%)(19 / 1, \mathrm{v} / \mathrm{v})$ to collect the HCAs. The collected solvent were evaporated using a stream of nitrogen and the final extracts were dissolved in $300 \mu \mathrm{L}$ methanol containing 4,7,8-TriMeIQx $(50 \mathrm{ppb})$ as an internal standard.

\section{Limit of detection (LOD) and limit of quantification (LOQ), standard curve, and recovery}

The peaks of targeted HCAs were identified by comparing their retention time and mass spectrum with peaks obtained from HCAs standards solutions. A mixtures of HCAs standard were prepared ranging from $1 \mathrm{ng} / \mathrm{mL}$ to $1000 \mathrm{ng} / \mathrm{mL}$ containing $50 \mathrm{ng}$ internal standards (4,7,8-TriMeIQx) were injected into the LC-MS/MS for tuning of the system prior to injection of samples extract. Standard curves (area ratio of each standard versus concentration) were plotted for individual HCAs in each mixture. The LOD and LOQ were determined based on the concentration with a signal-to-noise ratio 3:1 and 10:1, respectively. They were obtained by performing 
seven replications of the lowest acceptable standard concentration. A recovery study was performed by spiking the mixture solution (100 ppb) containing each of the following HCAs: IQx, IQ, MeIQx, MeIQ, 7,8-DiMeIQx, $\mathrm{PhIP}$, Harman, Norharman, and $\mathrm{A} \alpha \mathrm{C}$ in seven replications in grilled beef. Unspiked samples were considered as controls. The recoveries were determined (in percentage) by comparing the HCAs concentrations of the spiked samples with those of the control samples.

\section{Quantification of HCAs}

HCAs analysis was performed using an LC-MS/MS (AB Sciex 3200 QTrap LCMS/MS, MA, USA) system equipped with Eksigent 110 ultra-high performance liquid chromatography (UHPLC) system (Perkin Elmer Flexar FX15, MA, USA), an ESI (electron spray ionization) probe and TSQ Quantum quadrupole mass spectrometer detector. Multiple reaction monitoring (MRM) was carried out to screen samples in negative polarity. Prior to injection samples extracts, the LC-MS/MS instrument was tuned based on the unique fragments for each reference standards. The parent compounds were targeted and then fragmented to their unique fragment masses. Two fragment ions from the same compound were monitored for further confirmation purposes (Table 2). Then samples peaks were identified by comparing their mass spectral and retention time with reference standards. Fig. 1 shows the chromatogram of mixture HCAs standards at 1 ppb concentration. HPLC procedure described by (Barceló-Barrachina et al., 2006) was followed with minor modification (gradient program was modified). HCAs were separated with a Phenomenex Aqua C18 (Phenomenex, Torrance, CA, USA) reversed-phase column $(50 \mathrm{~mm} \times 2.1 \mathrm{~mm}, 5 \mu \mathrm{M})$. An aliquot $(10 \mu \mathrm{l})$ of mixture 9 HCAs standards and internal standard at different concentration of $1,5,10,25,50,75,100,200,500$ and $1000 \mathrm{ppb}$ was used to construct a 10-point standard curve for each compound. HCAs separation was achieved using binary mobile phase at a flow rate of $400 \mu \mathrm{l} / \mathrm{min}$. Solvent A: $30 \mathrm{mM}$ formic acid/ammonium formate $\mathrm{pH} 4.7$; solvent B: acetonitrile. The total running time was $10 \mathrm{~min}$ as follow gradient program: 0-6 min 5\% B to 100\% B, 6-8 min 100\% B, 8-10 min 5\% B to equilibrate the column. Each beef sample extract was passed through 
$0.22 \mu \mathrm{m}$ nylon syringe filter (Macherey-Nagel, Düren, Germany) prior to injection (10 $\mu$ l) into the HPLC system.

\section{Sensory evaluation}

The marinade formula with the optimum point of mixture design was selected based on the method described by Gibis and Weiss (2010) for sensory evaluation analysis using the 9-point hedonic scale as follows: $9=$ like extremely, 8 = like very much, 7 = like moderately, $6=$ like slightly, $5=$ neither like nor distike, $4=$ dislike

slightly, 3 = dislike moderately, 2 = dislike very much, and 1= dislike extremely. Unmarinated (control) and marinated beef samples (turmeric and lemon grass at $52.42: 47.57 \%$ ) were grilled in the same condition of the experiment $\left(240^{\circ} \mathrm{C}\right.$ for $\left.10 \mathrm{~min}\right)$. Exactly 60 untrained panelists consisting of 38 female and 22 male were requested to evaluate the color, tenderness, flavor, and overall acceptability of the samples from 1-9 points. The samples were labeled with random 3-digit codes and randomly served in order to the panelists. Plain water was provided to the assessors for mouth rinsing between samples to remove residual taste of previous samples. Collected data were analyzed through student's t-test in order to determine flavor desirability and overall acceptability.

\section{Mutagenicity test}

The marinated grilled beef sample $(5 \mathrm{~g})$ containing the optimized ratio of turmeric and lemon grass (52.42\%:47.57\%) and unmarinated beef sample ( $5 \mathrm{~g})$ were extracted by the method described earlier (Section 2.9). The only difference is that for mutagenicity test the final extracts were dissolved in $100 \mu \mathrm{L}$ DMSO $10 \%$ instead of $300 \mu \mathrm{L}$ methanol. The method described by Ames, McCann, and Yamasaki (1975) was applied for mutagenicity assay. Bacteria strains, Salmonella Typhimurium TA1535 (ATCC ® Number: 29629) and TA1537 (ATCC ® Number: 29630) were provided by The American Type Culture Collection (ATCC) Bacteria Department of Georgetown University, Washington, USA. S. Thyphimurim TA1535 detects base substitution 
mutations and $S$. Typhimurim TA1537 detects frameshift mutations. An aliquot $0.5 \mathrm{~mL}$ S9 rat liver enzymes (Sigma-Aldrich, St. Louis, MO, USA) were utilized for metabolic activation of HCAs. Since the HCAs exert their mutagenic activity only after metabolic activation, the presence of S9 is obligatory for mutagenicity test. It activates the exocyclic amine group of HCAs by N-hydroxylation and produces an intermediate which has been implicated in general toxicity and DNA damage. DMSO (10\%) was used as a negative control and benzo[a]pyrene $(\mathrm{BaP})(10 \mu \mathrm{g} /$ plate) was used as a positive control. Top agar, histidine-biotin solution $(0.5 \mathrm{mM})$, and minimal glucose plates were prepared as described by Maron and Ames (1983). An Aliquot (0.1 mL) of the overnight bacterial culture $\left(10^{8}\right), 0.5 \mathrm{~mL}$ of $\mathrm{S} 9$ fraction, $0.1 \mathrm{~mL}$ of sample extract and $0.5 \mathrm{~mL}$ of phosphate buffer were added to the test tube containing $2 \mathrm{~mL}$ of top agar warmed at $50^{\circ} \mathrm{C}$ in a water bath. The mixture was gently vortexed (IKA Vortex Genius3; IKA Werke GmbH and Co. KG, Staufen, Germany) for 3 seconds at low speed and poured onto plates containing a minimal glucose agar. After 1 hour, the plates were placed in an incubator at $37^{\circ} \mathrm{C}$, and they were counted for revertant colonies after $72 \mathrm{~h}$.

\section{Experimental design and statistical analysis}

A simplex centroid design was applied to define an optimum mixture proportion of the selected herbs and spices to reduce the amount of HCAs in grilled beef. Table 1 shows a matrix design which consists of 19 experimental points. The four independent variables (spices/herbs) in the mixture design consisted of turmeric $(\mathrm{X} 1)$, curry leaf $(\mathrm{X} 2)$, torch ginger $(\mathrm{X} 3)$, and lemon grass $(\mathrm{X} 4)$ have been studied at 7 levels namely $0(0 \%), 1 / 2$ (50\%), 1/3 (33\%), 1/4 (25\%), 1/8 (12.5\%), 5/8 (62.5\%), and $1(100 \%)$ (Table 1). The amounts of heterocyclic amines were defined as independent variables for the analysis. The experimental design, regression analysis, and optimization were performed using Minitab v.17 software (Version 16, Minitab Inc., State College, PA, USA). Numerical optimization was used in the Minitab software to identify the optimum proportion of marinade ingredients which result in the reduction of HCAs. Regression analysis offered quadratic regression 
model to simulate the optimized ratio of the marinade components. The standard form of the quadratic model is represented in the following equation:

(Eq. 2) $\quad \mathrm{Y}=\sum_{i=1}^{a} \beta i x i+\sum \sum_{i=1}^{q} \beta i j x i x j$

where $\mathrm{Y}$ is the predicted response, $\beta i$ is the regression coefficient for each linear effect terms, and $\beta i j$ is binary interaction effect terms.

\section{Results and discussion}

\section{Effects of combination of herbs and spices on concentration of HCAs}

Herbs and spices are rich in various phytochemicals reported to inhibit HCAs formation due to their antioxidant properties. They act as a radical scavenger to trap free radicals created in different pathways of HCAs formation (Gibis and Weiss 2012). In this study, a simplex centroid mixture design was applied to evaluate the effect of four different herbs/spices and their mixtures on the reduction of HCAs concentrations in grilled beef. The results presented in Table 3 show that the herbs and spices used in this study as well as their combinations positively inhibited HCAs formation in grilled beef. Concentration of IQ, IQx, 7,8 DiMeIQx, PhIP, Harman, Norharman, and $\mathrm{A} \alpha \mathrm{C}$ in the control sample were quantitated to be 4.6, 3.1, 1.7, 17.6, 45.6, 87.4, and 47.2 ng/g, respectively. They were higher than those measured in marinated grilled beef samples with exception of $\mathrm{PhIP}$ in grilled beef marinated with curry leaf. The concentrations of MeIQ and MeIQx both in control and marinated samples were lower than limit of detection (LOD) and treated as zero when calculating the mean values. Degradation of some heterocyclic amines at high temperatures reported by some researchers (Randel et al. 2007; Skog et al. 2000) might be the explanation of this phenomenon.

Although a number of studies (Ahn and Grün 2005; Damašius et al. 2011; Gibis and Weiss 2012; Jinap et al 2013; Quelhas et al. 2010) reported the effectiveness of using powders or natural extracts of herbs, spices, 
fruits, and plant seed oils on the reduction of the HCAs concentration in meat products, in some cases, plants extracts promoted the concentration of HCAs. A study by Damašius et al. (2011) demonstrated that using $0.2 \%$ and $0.5 \%$ extracts of oregano, thyme, and savory in raw beef samples (w/w) decreased the formation of PhIP; on the contrary, adding coriander, sweet grass, basil and rosemary extracts increased PhIP concentration in cooked beef. In another study, application of hibiscus extract in the broiled beef patties decreased the concentration of $\mathrm{PhIP}$ and MeIQx by approximately $40 \%$ and 50\%, respectively; on the contrary, it promoted the concentrations of Norharman and Harman (Gibis and Weiss, 2010). For the explanation of this phenomenon, it was presumed that hibiscus extract contributed other components such as glycosides to the HCAs pathways which can likely increase or inhibit the HCAs formation. Hence, in the present study, in order to clarify more precisely the inhibitory effect of herbs/spices on HCAs formation, in addition to antioxidant activity, concentration of HCAs precursors (glucose and free amino acids) of herbs and spices were evaluated.

As shown in Table 3, samples with binary mixture of marinade ingredients exhibited the lowest amount of total HCAs. The reduction of total HCAs content in the marinated samples with single herbs or spices ranged from $21.3 \%$ for curry leaf to $75.4 \%$ for turmeric; whereas, in combination of herbs and spices, the reduction increased to $94.8 \%$ in mixture of turmeric and lemon grass $(50: 50 \mathrm{w} / \mathrm{w})$ and $91.73 \%$ in mixture of turmeric and torch ginger $(50: 50 \mathrm{w} / \mathrm{w})$. These results were expected, because the highest scavenging of $\mathrm{DPPH}^{+}$and ferric ion reduction belonged to turmeric which might lead to higher reduction of total HCAs (75\%). Surprisingly, although antioxidant activity of curry leaf was far higher than torch ginger and lemon grass (Table 4), it only reduced total HCAs at $21.3 \%$ compared to torch ginger and lemon grass at $66.96 \%$ and $71.94 \%$, respectively. In the sample marinated with curry leaf, the concentration of PhIP was around 3-times more than in those of unmarinated sample (control) and the concentrations of Norharman slightly decreased. The high concentration of phenylalanine $(2.8 \mu \mathrm{mol} / \mathrm{g} \mathrm{dw})$ and tryptophan $(4.0 \mu \mathrm{mol} / \mathrm{g} \mathrm{dw})$ in curry leaf which are the precursors of PhIP (Turesky 2007) and Norharman (Herraiz 2004, 2000a ), respectively could be the explanation for the high 
level of PhIP (48.6 ng/g) and Norharman $(82 \mathrm{ng} / \mathrm{g})$ in samples marinated with curry leaf. Therefore, despite the strong antioxidant activity of turmeric which is more likely the main reason for reduction of HCAs concentration in marinated grilled beef, the lower level of total amino acids in turmeric $(66.2 \mu \mathrm{mol} / \mathrm{g} \mathrm{dw})$ and lemon grass $(18.3 \mu \mathrm{mol} / \mathrm{g} \mathrm{dw})$ than curry leaf $(119.6 \mu \mathrm{mol} / \mathrm{g} \mathrm{dw})$ and torch ginger $(96.8 \mu \mathrm{mol} / \mathrm{g} \mathrm{dw}) \mathrm{might}$ be the other explanation of the lowest concentration of total HCAs in grilled beef marinated with this mixture. In a study by Skog et al. (2000), adding tryptophan and phenylalanine at 5-fold original level to meat juice model system resulted in markedly increase in the level of Harman (10 fold) and PhIP (2-fold), while adding glucose negligibly increased or even reduced the level of these compounds.

It was reported that glucose could enhanced or inhibited the HCAs formation depending on its concentration (Murkovic 2004). In a study conducted by Jägerstad et al. (1991), optimum HCAs yield were obtained when the concentration of glucose was around half of the molar concentration of creatin(in)e or amino acid, and excessive concentration of glucose either in model system or in real meat system reduce the amount of HCAs. Hence, higher concentration of glucose in turmeric $(405.1 \mu \mathrm{mol} / \mathrm{g} \mathrm{dw})$ and lemon grass $(108.8 \mu \mathrm{mol} / \mathrm{g} \mathrm{dw})$ (Table 2) compared with curry leaf and torch ginger can be the other explanation of the highest reduction of total HCAs in the mixture of turmeric and Aemon grass. The mechanisms behind the inhibitory effect of glucose on HCAs concentration are not elucidated yet. However, it is postulated that increasing the concentration of sugar as compared with the amino acids in model system led to formation of other Maillard reaction products which might compete with the compounds creating the HCAs (Skog and Jägerstad 1990).

The results in Table 3 show that since the curry leaf was eliminated from the mixtures and substituted by turmeric and lemon grass, concentration of total HCAs diminished. The results can be attributed to three factors: 1) the high antioxidant activity of turmeric which can scavenge free radicals formed in the pathway of HCAs formation, 2) the high glucose content of turmeric and lemongrass which can mask creatine and deplete it from 
the reaction pathway 3) the high amino acid content of curry leaf which can enhance the concentration of some HCAs.

\section{Antioxidant properties and concentration of some bioactive compounds in herb/spices}

The results presented in Table 4 indicate that FRAP values varied significantly $(\mathrm{p}<0.05)$ among different sample extracts. Turmeric exhibited the strongest FRAP with $55.8 \mathrm{mg}$ QE/g CE followed by curry leaf, torch ginger and lemon grass with 52.4, 40.01 and $8.4 \mathrm{mg} \mathrm{QE} / \mathrm{g} \mathrm{CE}$, respectively. The trend of DPPH\% showed a parallel trend with FRAP where turmeric with $47.4 \%$ was the greatest DPPH radical inhibitor followed by curry leaf with $41.7 \%$, torch ginger with $27 \%$, and lemon grass with $10.37 \%$ which showed the lowest DPPH\%. The high quantity of curcuminoids, especially curcumin $(280 \mathrm{mg} / \mathrm{g} \mathrm{dw})$ may explain the strong antioxidant activity of turmeric compared with other herbs/spices used. The presence of phenolic compounds in turmeric, curry leaf, torch ginger and lemon grass were demonstrated in HPLC profiles of these materials (Fig. 2). They were identified by comparing their UV spectra with those of standards, and they were quantified by peak height ratio method (Table 4). The inhibitory activity of some phenolic compounds on HCAs formation were reported in earlier studies (Oguri et al. 1998; Cheng et al. 2007; Cheng et al. 2009; Moon and Shin 2013). Therefore, the reduction of HCAs formation in grilled beef might result from the presence of antioxidants in the herbs and spices used for marinating beef.

\section{Amino acids, sugar, creatine and fat content}

Amino acids composition and glucose content were analyzed to give insight into the concentration of glucose and amino acids in beef and marinade ingredients. The results of free amino acids, glucose and creatine content are summarized in Table 5. The total free amino acids in fresh beef was $25.9 \mu \mathrm{mol} / \mathrm{g}$ fresh weight. Among four herbs/ spices tested in this study, curry leaf exhibited the highest quantity of free amino acids content (119.6 $\mu \mathrm{mol} / \mathrm{g}$ dried weight), while lemon grass showed the lowest total amino acids content $(18.3 \mu \mathrm{mol} / \mathrm{g} \mathrm{dw})$. In beef 
sample, alanine with $5.1 \mu \mathrm{mol} / \mathrm{g}$ fw was the dominant amino acid followed by glutamine with $4.7 \mu \mathrm{mol} / \mathrm{g}$ fw. The results obtained in this study are in agreement with those reported by Gibis and Weiss (2010) and Skog et al. (2000) who found that the concentration of alanine and glutamine were higher than other amino acids in beef sample. The content of total amino acids in our study is lower than the previous studies, because they were reported based on freeze dried weight of beef samples, while in the present study they were reported based on the weight of fresh beef. In turmeric and lemon grass, asparagine had the highest concentration, and in curry leaf and torch ginger, glutamine ranked the highest amino acid amongst the others. The glucose and creatine content of the beef sample were 14.4 and $33 \mu \mathrm{mol} / \mathrm{g} \mathrm{fw}$, respectively which are almost identical with the results obtained by Arvidsson et al. (1997). Because there were no studies in the literature measuring amino acids content of the herbs and spices used in the present study, comparison our finding with others was impossible. The fat content of beef was 12.4\% which was agreement with the results reported by Polak, Andrenšek, Žlender, and Gašperlin (2009).

\section{Evaluation of limit of detection (LOD) and limit of quantification (LOQ), standard curve and recovery}

Limit of detection (LOD), limit of quantitation (LOQ), and recovery of HCAs were presented in Table 2. The LOD and LOQ for HCAs ranged from 0.016 to $0.066 \mathrm{ng} / \mathrm{g}$ and 0.036 to $0.198 \mathrm{ng} / \mathrm{g}$, respectively. The efficiency of HCAs recovery for beef samples ranged from 54.2\% for Harman to 78.6\% for MeIQx which are comparable with the recovery of HCAs reported by Oz et al. (2010) between 32 and 66\% and Ruan et al. (2014) from 47.3 to $64.4 \%$.

\section{Fitting the model}

All terms which were significant $(\mathrm{p}<0.05)$ were remained in the quadratic model and refitted to gain the final reducing model. All linear terms of main factors must always be included in the design because once the proportion of one factor changes in mixture, it leads to change the proportion of the other factors. Therefore, the 
p-value of main factors would not be presented in Table 6. The significance of the estimated regression coefficient for each response variable, after final reducing model, was assessed by its F-ratio at a probability (pvalue) of 0.05 . The adequacy of the response models was determined using model analysis, such as coefficient of-determination (R2). The mixture analysis revealed that the relationships of the marinade components, turmeric (X1), curry leaf (X2), torch ginger (X3), and lemon grass (X4) with IQ, PhIP, Harman, Norharman, and $\mathrm{A} \alpha \mathrm{C}$ could be explained by significant quadratic regression equation (Table 6). The satisfactory coefficient of determination $\left(\mathrm{R}^{2}\right)$ from 72.39 to 94.05 indicated a valid fitted model.

\section{Optimization and validation procedures}

The numerical multiple optimizations revealed that marinated grilled beef with the least content of mentioned heterocyclic amines was predicted to be obtained from the mixture of turmeric and lemon grass with a proportion of $52.42: 47.57 \%(\mathrm{w} / \mathrm{w})$. At this optimum marinade ingredient ratio, the corresponding predicted response values for the minimum amount of IQ, PhIP, Harman, Norharman, and A $\alpha$ C were predicted to be 2.2, $1.4,0.5,2.8$, and $1.2 \mathrm{ng} / \mathrm{g}$, respectively whereby the total desirability to be 0.9996 . The adequacy of predicted optimum marinade was evaluated using the t-test. The insignificant difference $(\mathrm{p}>0.05)$ observed between the experimental and predicted values confirmed the validity of the final reduced model.

\section{Sensory evaluation}

The analysis of sensory data (Table 7) showed that marinating with mixture of turmeric and lemon grass $(8 \mathrm{~h})$ improved the color and flavor characteristics of the grilled beef samples. For this reason, the assessors gave higher scores to those of attributes in marinated samples compared to control samples. The attributes of overall acceptability for marinated samples received higher score than those of control samples, indicating good sensory quality; whereas, results of tenderness revealed no significant differences $(\mathrm{p}>0.05)$ between marinated and unmarinated (control) sample. 


\section{Mutagenicity test}

The results showed that the grilled beef samples marinated by optimized marinade formula (turmeric:lemon grass, 52.42\%:47.57\%) had a lower bacteria colony count (Fig. 3). The mutagenic activity of control grilled beef (unmarinated beef) was 78 revertants per gram of beef (revertants $/ g$ ) for $S$. Typhimurium TA1535 and 48 revertants/g for $S$. Typhimurium TA1537. However, the mutagenic activities of BaP, which was applied as positive control, was rather high 109 revertants $/ \mu \mathrm{g}$ for S. Typhimurium TA1535 and 114 revertants $/ \mu \mathrm{g}$ for S. Typhimurium TA1537. Marinated beef with optimized marinade formula before grilling reduced the mutagenicity of grilled beef to a level of about 32 revertants/g for S. Typhimurium DA1535 and about 26 revertants/g for $S$. Typhimurium TA1537 (Table 8). Comparison of mutagenic activity of marinated and unmarinated grilled beef (t-test) using Ames test demonstrated that combination of turmeric and lemon grass significantly $(\mathrm{p}<0.05)$ reduced the mutagenicity of grilled beef, which also proved the reduction of HCAs concentration in this sample.

The results of this study were comparable to those reported by Nerurkar et al. (1999) who observed that fried beef steaks marinated with turmeric-garlic sauce resulted in $34 \%$ and $45 \%$ lower mutagenic activity at 10 and 15 min barbequing, respectively. Shin and Ustunol (2004) reported reduction in overall mutagenicity in chicken breast and fried beef steak marinated with lemon juice, clover, garlic, soy sauce, and buckwheat honey. Tikkanen et al. (1996) observed a reduction of mutagenic activity of marinated grilled chicken by $28 \%$ on $S$. Typhimurium TA98 that reflected the marinade effect on the concentration of HCAs.

\section{Conclusions}

It can be concluded that all selected herbs and spices utilized in this study possessed antioxidant activity due to presence of phenolic compounds which can diminish total HCAs concentration in marinated grilled beef. Different proportions of mixtures of herbs/spices demonstrated variation in reduction of HCAs level. 
Combination of turmeric and lemon grass $(52.42 \%: 47.57 \%)$ gave the satisfactory results for the maximum reduction of the amount of total HCAs which resulted in lower mutagenicity of marinated beef compared to unmarinated sample. Results indicated that besides the antioxidant property which is a key factor in the inhibition of HCAs formation, other factors in marinade ingredients such as concentration of HCAs precursors, glucose and amino acids, are also effective on HCAs formation or reduction. Therefore, with a proper choice of marinade components, it would be possible to minimize HCAs concentration and mutagenicity of grilled beef.

\section{Acknowledgements}

We would like to thank to Ministry of Science Technology and Innovation (MOSTI) of Malaysia for the financial support of this work through the project 02-01-04-SF1436.

\section{Conflict of interest}

490 The authors have declared no potential conflict of interests

\section{References}

Ahn, J, Grün, IU, (2005). Heterocyclic amines: 2. Inhibitory effects of natural extracts on the formation of polar and nonpolar heterocyclic amines in cooked beef. Journal of Food Science, 70(4), 263-268.

Álvarez-Casas M, García-Jares C, Llompart M, Lores M, (2014). Effect of experimental parameters in the pressurized solvent extraction of polyphenolic compounds from white grape marc. Food Chemistry, 157, 524532.

Ames BN, McCann J, Yamasaki E. (1975). Methods for detecting carcinogens and mutagens with the Salmonella/mammalian-microsome mutagenicity test. Mutation Research/Environmental Mutagenesis and Related Subjects, 31(6), 347-363. 
Alaejos MS, Pino V, Afonso AM. (2008). Metabolism and toxicology of heterocyclic aromatic amines when consumed in diet: Influence of the genetic susceptibility to develop human cancer. A review. Food Research International, 41(4), 327-340.

Arvidsson P, Boekel M, Skog K, Jägerstad M. (1997). Kinetics of formation of polar heterocyclic amines in a meat model system. Journal of Food Science, 62(5), 911-916.

Badawy A, Morgan C, Turner J. (2008). Application of the Phenomenex EZ: faast ${ }^{\mathrm{TM}}$ amino acid analysis kit for rapid gas-chromatographic determination of concentrations of plasma tryptophan and its. Amino Acids, 34:587596.

Barceló-Barrachina E, Moyano E, Galceran M, Lliberia J, Bagó B, Cortes, M. (2006). Ultra-performance liquid chromatography-tandem mass spectrometry for the analysis of heterocyclic amines in food. Journal of Chromatography A, 1125(2), 195-203.

Carpenter C. (2010). Determination of fat content. In S. Nielson (Ed.), Food analysis laboratory manual, (pp. 29-37). New York. Springer

Cheng KW, Chen F, Wang M. (2007). Inhibitory activities of dietary phenolic compounds on heterocyclic amine formation in both chemical model system and beef patties. Molecular Nutrition and Food Research, 51(8), 969-976.

Cheng KW, Wong CC, Chao J, Lo C, Chen,F, Chu IK, Wang M. (2009). Inhibition of mutagenic PhIP formation by epigallocatechin gallate via scavenging of phenylacetaldehyde. Molecular Nutrition and Food Research, 53(6), 716-725.

Damašius J, Venskutonis P, Ferracane R, Fogliano V. (2011). Assessment of the influence of some spice extracts on the formation of heterocyclic amines in meat. Food Chemistry, 126(1), 149-156.

Del Campo, G, Gallego B, Berregi I, Casado JA. (1998). Creatinine, creatine and protein in cooked meat products. Food Chemistry, 63(2), 187-190.

Figueirinha A, Paranhos A, Pérez-Alonso JJ, Santos-Buelga C, Batist, MT. (2008). Cymbopogon citratus leaves: Characterization of flavonoids by HPLC-PDA-ESI/MS/MS and an approach to their potential as a source of bioactive polyphenols. Food Chemistry, 110(3), 718-728. 
Gibis M, Kruwinnus M, Weiss J. (2015). Impact of different pan-frying conditions on the formation of heterocyclic aromatic amines and sensory quality in fried bacon. Food Chemistry, 168, 383-389.

Gibis M, Weiss J. (2010). Inhibitory effect of marinades with hibiscus extract on formation of heterocyclic aromatic amines and sensory quality of fried beef patties. Meat Science, 85, 735-742.

Gibis M, Weiss J. (2012). Antioxidant capacity and inhibitory effect of grape seed and rosemary extract in marinades on the formation of heterocyclic amines in fried beef patties. Food Chemistry, 134, 766-774.

Hasnol N, Jinap S, Sanny M, 2014. Effect of different types of sugars in a marinating formulation on the formation of heterocyclic amines in grilled chicken. Food Chemistry, 145, 514-521.

Herraiz T. (2000). Tetrahydro- $\beta$-carbolines, Potential Neuroactive Alkaloids, in Chocolate and Cocoa. Journal of Agricultural and Food Chemistry, 48(10), 4900-4904.

Herraiz T. (2004). Relative exposure to $\beta$-carbolines norharman and harman from foods and tobacco smoke. Food Additives and Contaminants, 21(11), 1041-1050.

Jägerstad M, Skog K, Grivas S, Olsson K. (1991). Formation of heterocyclic amines using model systems. Mutation Research/Genetic Toxicology, 259(3-4), 219-233.

Jinap S, Mohd-Mokhtar M, Farhadian A, Hasnol N, Jaafar S, Hajeb P. (2013). Effects of varying degrees of doneness on the formation of heterocyclic aromatic amines in chicken and beef satay. Meat Science 94, 202207.

Kizil M, Oz F, Besler HT. (2011). A review on the formation of carcinogenic/mutagenic heterocyclic aromatic amines. Journal of Food Processing and Technology, 2(5), 2-5.

Maheshwari RK, Sing, AK, Gaddipati J, Srimal RC. (2006). Multiple biological activities of curcumin: a short review. Life Sciences, 78(18), 2081-2087.

Maron DM, Ames BN. (1983). Revised methods for the Salmonella mutagenicity test. Mutation Research/Environmental Mutagenesis and Related Subjects, 113(3-4), 173-215.

Murkovic M. (2004). Formation of heterocyclic aromatic amines in model systems. Journal of Chromatography B, 802(1), 3-10. 
Moon, SE, Shin HS. (2013). Inhibition of mutagenic 2-amino-1-methyl-6-phenylimidazo [4, 5-b] pyridine (PhIP) formation using various food ingredients in a model systems. Food Science and Biotechnology, 22(2), 323-329.

Nerurkar PV, Marchand LL, Cooney RV. (1999). Effects of marinating with Asian marinades or western barbecue sauce on PhIP and MeIQx formation in barbecued beef. Nutrition and Cancer, 34(2), 147-152.

Oguri A, Suda M ,Totsuka Y, Sugimura T, Wakabayashi K. (1998). Inhibitory effects of antioxidants on formation of heterocyclic amines. Mutation Research/Fundamental and Molecular Mechanisms of Mutagenesis, 402(1), 237-245.

Oz F, Kaban G, Kaya M. (2010). Effects of cooking methods and levels on formation of heterocyclic aromatic amines in chicken and fish with Oasis extraction method. LWT-Food Science and Technology 43, 1345-1350.

Oz F, Kaya M. (2011). The inhibitory effect of black pepper on formation of heterocyclic aromatic amines in high-fat meatball. Food Control 22, 596-600.

Phenomenex EZ:faast (easy fast) amino acid sample testing kit (2003). User guide, Phenomenex, 411 Madrid Avenue, Torrance, CA 90501-1430, USA (http://www.phenomenex.com)

Polak T, Andrenšek, S., Žlender, B., \& Gašperlin, L. (2009). Effects of ageing and low internal temperature of grilling on the formation of heterocyclic amines in beef Longissimus dorsi muscle. LWT-Food Science and Technology, 42(1), 256-264.

Polson C, Sarkar P, Incledon B, Raguvaran V, Grant R. (2003). Optimization of protein precipitation based upon effectiveness of protein removal and ionization effect in liquid chromatography-tandem mass spectrometry. Journal of Chromatography B, 785, 263-275.

PuangsombatnK, Gadgil P, Houser TA, Hunt MC, Smith JS. (2012). Occurrence of heterocyclic amines in cooked meat products. Meat Science 90, 739-746.

Puangsombat K, Jirapakkul W, Smith JS. (2011). Inhibitory activity of Asian spices on heterocyclic amines formation in cooked beef patties. Journal of Food Science, 76, 174-180.

Quelhas I, Petisca C, Viegas O, Melo A, Pinho O, Ferreira I. (2010). Effect of green tea marinades on the formation of heterocyclic aromatic amines and sensory quality of pan-fried beef. Food Chemistry, 122, 98-104. 
Randel, G., Balzer, M., Grupe, S., Drusch, S., Kaina, B., Platt, K. L., and Schwarz, K. (2007). Degradation of heterocyclic aromatic amines in oil under storage and frying conditions and reduction of their mutagenic potential. Food and Chemical Toxicology, 45(11), 2245-2253.

Ruan E, Juárez M, Thacker R, Yang X, Dugan M, Aalhus J. (2014). Dietary vitamin E effects on the formation of heterocyclic amines in grilled lean beef. Meat Science, 96, 849-853.

Shin H, Ustunol Z. (2004). Influence of Honey- containing Marinades on Heterocyclic Aromatic Amine Formation and Overall Mutagenicity in Fried Beef Steak and Chicken Breast. Journal of Food Science, 69, $147-$ 153.

Shon MY, Kim TH, Sung NJ. (2003). Antioxidants and free radical scavenging activity of Phellinus baumii (Phellinus of Hymenochaetaceae) extracts. Food Chemistry, 82, 593-597.

Singh AP, Wilson T, Luthria D, Freeman MR, Scott RM, Bilenker D, Shah S, Somasundaram ., Vorsa, N. (2011). LC-MS-MS characterisation of curry leaf flavonols and antioxidant activity. Food Chemistry, 127, 8085 .

Skog K, Jägerstad M. (1990). Effects of monosaccharides and disaccharides on the formation of food mutagens in model systems. Mutation Research/Fundamental and Molecular Mechanisms of Mutagenesis, 230(2), 263272.

Skog K, Solyakov A, Jägerstad M. (2000). Effects of heating conditions and additives on the formation of heterocyclic amines with reference to amino-carbolines in a meat juice model system. Food Chemistry, 68, 299308.

Szterk A. (2013). Chemical state of heterocyclic aromatic amines in grilled beef: Evaluation by in vitro digestion model and comparison of alkaline hydrolysis and organic solvent for extraction. Food and Chemical Toxicology, 62, 653-660.

Szterk A. (2015a). Acridine derivatives (PANHs, azaarenes) in raw, fried or grilled pork from different origins, and PANH formation during pork thermal processing. Journal of Food Composition and Analysis, 43, $18-24$. 
Szterk A. (2015b). Heterocyclic aromatic amines in grilled beef: The influence of free amino acids, nitrogenous bases, nucleosides, protein and glucose on HAAs content. Journal of Food Composition and Analysis, 40, 3946.

Szterk A., Jesionkowska K. (2015). Influence of the cold storage time of raw beef meat and grilling parameters on sensory quality and content of heterocyclic aromatic amines. LWT - Food Science and Technology, 61(2), 299-308.

Szterk A, Roszko M, Małek K, Kurek M, Zbieć M, Waszkiewicz-Robak B. (2012). Profiles and concentrations of heterocyclic aromatic amines formed in beef during various heat treatments depend on the time of ripening and muscle type. Meat Science, 92(4), 587-595.

Szterk A, Waszkiewicz-Robak B. (2014). Influence of selected quality factors of beef on the profile and the quantity of heterocyclic aromatic amines during processing at high temperature. Meat Science, 96(3), 11771184.

Tikkanen L, Latva-Kala K, Heiniö RL. (1996). Effect of commercial marinades on the mutagenic activity, sensory quality and amount of heterocyclic amines in chicken grilled under different conditions. Food and Chemical Toxicology, 34(8), 725-730.

Toda S, Miyase T, Arichi H, Tanizawa H, Takino Y. (1985). Natural antioxidants. III. Antioxidative components isolated from rhizome of Curcuma longa L. Chemical and Pharmaceutical Bulletin, 33(4), 17251728.

Turesky RJ. (2007). Formation and biochemistry of carcinogenic heterocyclic aromatic amines in cooked meats. Toxicology Letters, 168(3), 219-227.

Yu D, Chen MS, Yu SJ. (2016). Effect of sugarcane molasses extract on the formation of 2-amino-1-methyl-6phenylimidazo [4, 5-b] pyridine (PhIP) in a model system. Food Chemistry, 197, 924-929.

Wijekoon MJO, Bhat R, Karim AA. (2011). Effect of extraction solvents on the phenolic compounds and antioxidant activities of bunga kantan (Etlingera elatior Jack.) inflorescence. Journal of Food Composition and Analysis, 24(4), 615-619. 
Wichitnithad W, Jongaroonngamsang N, Pummangura S, Rojsitthisak P. (2009). A simple isocratic HPLC method for the simultaneous determination of curcuminoids in commercial turmeric extracts. Phytochemical Analysis, 20(4), 314-319.

Yan SW, Rahmat A. (2010). Comparison of total phenolic contents and antioxidant activities of turmeric leaf, pandan leaf and torch ginger flower. International Food Research Journal 17, 417-423.

Zheng W, Lee, SA. (2009). Well-done meat intake, heterocyclic amine exposure, and cancer risk. Nutrition and Cancer, 61(4), 437-446. 
Table 1

Matrix of the simple centroid mixture design for optimization the HCAs reduction

\begin{tabular}{|c|c|c|c|c|c|c|c|c|}
\hline \multirow[b]{2}{*}{ No } & \multicolumn{4}{|c|}{ Variables $(\%)$} & \multirow[b]{2}{*}{$\begin{array}{l}\text { Turmeric } \\
(\mathrm{g} / 100 \mathrm{~g})\end{array}$} & \multirow[b]{2}{*}{$\begin{array}{l}\text { Curry leaf } \\
(\mathrm{g} / 100 \mathrm{~g})\end{array}$} & \multirow[b]{2}{*}{$\begin{array}{l}\text { Torch ginger } \\
(\mathrm{g} / 100 \mathrm{~g})\end{array}$} & \multirow[b]{2}{*}{$\begin{array}{c}\text { Lemon gr } \\
(\mathrm{g} / 100 \mathrm{~g})\end{array}$} \\
\hline & $\begin{array}{l}\text { Turmeric } \\
\text { (X1) }\end{array}$ & $\begin{array}{l}\text { Curry leaf } \\
\text { (X2) }\end{array}$ & $\begin{array}{l}\text { Torch ginger } \\
\text { (X3) }\end{array}$ & $\begin{array}{l}\text { Lemon grass } \\
\text { (X4) }\end{array}$ & & & & \\
\hline 1 & 100 & 0 & 0 & 0 & 3 & 0 & 0 & 0 \\
\hline 2 & 0 & 100 & 0 & 0 & 0 & 3 & 0 & 0 \\
\hline 3 & 0 & 0 & 100 & 0 & 0 & 0 & 3 & 0 \\
\hline 4 & 0 & 0 & 0 & 100 & 0 & 0 & 0 & 3 \\
\hline 5 & 50 & 50 & 0 & 0 & 1.5 & 1.5 & 0 & 0 \\
\hline 6 & 50 & 0 & 50 & 0 & 1.5 & 0 & & 0 \\
\hline 7 & 50 & 0 & 0 & 50 & 1.5 & 0 & & 1.5 \\
\hline 8 & 0 & 50 & 50 & 0 & 0 & 1.5 & & 0 \\
\hline 9 & 0 & 50 & 0 & 50 & 0 & 1.5 & 0 & 1.5 \\
\hline 10 & 0 & 0 & 50 & 50 & 0 & 0 & 1.5 & 1.5 \\
\hline 11 & 33.3 & 33.3 & 33.3 & 0 & 1 & & 1 & 0 \\
\hline 12 & 33.3 & 33.3 & 0 & 33.3 & 1 & 1 & 0 & 1 \\
\hline 13 & 33.3 & 0 & 33.3 & 33.3 & 1 & 0 & 1 & 1 \\
\hline 14 & 0 & 33.3 & 33.3 & 33.3 & 0 & 1 & 1 & 1 \\
\hline 15 & 25 & 25 & 25 & 25 & 0. & 0.75 & 0.75 & 0.75 \\
\hline 16 & 62.5 & 12.5 & 12.5 & 12.5 & 1.875 & 0.375 & 0.375 & 0.375 \\
\hline 17 & 12.5 & 62.5 & 12.5 & 12.5 & 0.375 & 1.875 & 0.375 & 0.375 \\
\hline 18 & 12.5 & 12.5 & 62.5 & 12.5 & 0.375 & 0.375 & 1.875 & 0.375 \\
\hline 19 & 12.5 & 12.5 & 12.5 & 62.5 & 0.375 & 0.375 & 0.375 & 1.875 \\
\hline
\end{tabular}


Table 2

Limit of detection (LOD), Limit of quantification (LOQ), recovery and fragment ions of HACs

\begin{tabular}{|c|c|c|c|c|c|c|}
\hline \multirow[t]{2}{*}{ Compound } & \multirow{2}{*}{$\begin{array}{l}\text { LOD } \\
(\mathbf{n g} / \mathbf{g})\end{array}$} & \multirow{2}{*}{$\begin{array}{l}\text { LOQ } \\
(\mathrm{ng} / \mathrm{g})\end{array}$} & \multicolumn{2}{|c|}{ Recovery } & \multicolumn{2}{|c|}{ Fragment ions } \\
\hline & & & Value (\%) & SD & ms & $\mathrm{ms}^{2}$ \\
\hline IQ & 0.052 & 0.156 & 62.4 & 2.3 & 199.08 & $184.2,157.3$ \\
\hline IQx & 0.061 & 0.183 & 70.2 & 2.1 & 200.04 & $185.1,187.7$ \\
\hline MeIQ & 0.085 & 0.255 & 72.3 & 1.8 & 213.09 & $198.2,197.7$ \\
\hline MeIQx & 0.066 & 0.198 & 78.6 & 1.6 & 214.07 & $199.1,131.1$ \\
\hline 7,8 DiMeIQx & 0.032 & 0.096 & 68.4 & 2.4 & 228.11 & $213.3,115.1$ \\
\hline PhIP & 0.062 & 0.186 & 62.1 & 2.7 & 225.11 & $210.2,140.1$ \\
\hline Harman & 0.022 & 0.066 & 54.2 & 1.5 & 183.11 & $115.2,89.1$ \\
\hline Norharman & 0.016 & 0.048 & 66.3 & 1.9 & 169.13 & 115. $1,89.1$ \\
\hline $\mathrm{A \alpha C}$ & 0.021 & 0.036 & 61.7 & 1.3 & 184.16 & $140.1,116.2$ \\
\hline
\end{tabular}


Table 3

Concentration of HCAs in different marinated beef samples

"BLD: Below Limit of Detection

Note: Values display the mean values of triplicate determinations \pm SD

\begin{tabular}{|c|c|c|c|c|c|c|c|c|c|c|}
\hline \multirow[b]{2}{*}{ No } & \multicolumn{6}{|c|}{ Polar HCAs (ng/g) } & \multicolumn{3}{|c|}{ Non polar HCAs (ng/g) } & \multirow[t]{2}{*}{ Total I } \\
\hline & IQ & IQx & MeIQ & MeIQx & $\begin{array}{l}\text { 7,8 } \\
\text { DiMeIQx }\end{array}$ & PhIP & Harman & Norharman & Ag & \\
\hline 1 & $2.5 \pm 0.1$ & $2.1 \pm 0.3$ & BLD & BLD & $0.9 \pm 0.2$ & $7.2 \pm 0.4$ & $11.0 \pm 1.5$ & $16.4 \pm 2.2$ & $1.0 \pm \pm .3$ & $51.1 \pm 6$ \\
\hline 2 & $2.3 \pm 0.3$ & $1.3 \pm 0.2$ & BLD & BLD & $1.1 \pm 0.2$ & $48.6 \pm 2.5$ & $14.0 \pm 3.8$ & $82.0 \pm 2.5$ & $13.7 \pm 1.3$ & $163.1 \pm$ \\
\hline 3 & $3.0 \pm 0.1$ & $2.8 \pm 0.2$ & BLD & BLD & $0.9 \pm 0.2$ & $8.4 \pm 1.9$ & $10.2 \pm 2.2$ & $34.3 \pm 2.3$ & $8.8 \pm 1.5$ & $68.5 \pm 8$ \\
\hline 4 & $2.78 \pm 0.1$ & $2.2 \pm 0.2$ & BLD & BLD & BLD & BLD & $9.2 \pm 2.0$ & & $11.1 \pm 1.4$ & $58.1 \pm 7$ \\
\hline 5 & $3.4 \pm 0.5$ & $2.5 \pm 0.4$ & BLD & BLD & $1.1 \pm 0.2$ & $5.6 \pm 1.7$ & $12.1 \pm 1.7$ & $50.6 \pm 4.0$ & $11.5 \pm 2.1$ & $86.9 \pm 1$ \\
\hline 6 & $2.4 \pm 0.3$ & $0.5 \pm 0.0$ & BLD & BLD & $0.9 \pm 0.2$ & BLD & $3.1 \pm 1.0$ & $7,1 \pm 1.8$ & $3.1 \pm 1.0$ & $17.1 \pm 4$ \\
\hline 7 & $2.2 \pm 0.6$ & $\mathrm{BLD}^{*}$ & BLD & BLD & $0.9 \pm 0.2$ & BLD & $1.1 \pm 0.2$ & 5. $6 \pm 1.3$ & $1.1 \pm 0.4$ & $10.9 \pm 2$ \\
\hline 8 & $2.2 \pm 0.3$ & BLD & BLD & BLD & $1.0 \pm 0.4$ & BLD & $4.7 \pm 1.1$ & $30.6 \pm 3.2$ & $4.7 \pm 1.2$ & $43.2 \pm 6$ \\
\hline 9 & $2.6 \pm 0.1$ & $2.0 \pm 0.3$ & BLD & BLD & $1.0 \pm 0.3$ & $11.4 \pm 1.6$ & $4.3 \pm 1.1$ & $36.0 \pm 3.6$ & $4.7 \pm 1.3$ & $62.1 \pm 4$ \\
\hline 10 & $2.5 \pm 0.1$ & BLD & BLD & BLD & $0.8 \pm 0.1$ & $7.1 \pm 0.7$ & $3.6 \pm 0.4$ & $10.6 \pm 1.8$ & $3.6 \pm 1.0$ & $28.3 \pm 4$ \\
\hline 11 & $2.4 \pm 0.3$ & $1.1 \pm 0.1$ & BLD & BLD & $0.9 \pm 0.2$ & & $1.7 \pm 0.9$ & $10.8 \pm 2.2$ & $2.3 \pm 0.8$ & $22.4 \pm 4$ \\
\hline 12 & $2.6 \pm 0.5$ & $0.9 \pm 0.1$ & BLD & BLD & $1.1 \pm 0.5$ & $2.9 \pm 1.0$ & $4.4 \pm 1.4$ & $22.6 \pm 2.5$ & $3.6 \pm 0.9$ & $38.2 \pm 6$ \\
\hline 13 & $2.2 \pm 0.6$ & BLD & BLD & BLD & BLD & BLD & $1.8 \pm 0.8$ & $9.0 \pm 1.8$ & $2.0 \pm 0.8$ & $15.1 \pm 3$ \\
\hline 14 & $2.2 \pm 0.6$ & $2.4 \pm 0.2$ & BLD & BLD & $1.0 \pm 0.3$ & $0.6 \pm 0.1$ & $2.8 \pm 0.9$ & $16.9 \pm 2.0$ & $3.1 \pm 0.6$ & $29.1 \pm 4$ \\
\hline 15 & $3.4 \pm 0.7$ & $1.4 \pm 0.2$ & BLD & BLD & $0.9 \pm 0.1$ & BLD & $3.1 \pm 1.0$ & $17.5 \pm 2.8$ & $3.4 \pm 0.7$ & $29.6 \pm 5$ \\
\hline 16 & $2.94 \pm 0.3$ & $1.8 \pm 0.3$ & BLD & BLD & BLD & $10.3 \pm 2.3$ & $3.0 \pm 0.6$ & $11.9 \pm 2.1$ & $3.3 \pm 0.5$ & $33.3 \pm 4$ \\
\hline 17 & $2.4 \pm 0.2$ & BLD & BLD & BLD & & $10.1 \pm 1.1$ & $2.5 \pm 0.3$ & $35.0 \pm 2.6$ & $6.4 \pm 1.2$ & $57.4 \pm 5$ \\
\hline 18 & $2.2 \pm 0.1$ & $1.7 \pm 0.2$ & BLD & BLD & $0.9 \pm 0.3$ & BLD & $2.9 \pm 0.2$ & $11.9 \pm 1.3$ & $2.7 \pm 0.7$ & $22.2 \pm 2$ \\
\hline 19 & $2.3 \pm 0.1$ & BLD & BLD & BID & BLD & BLD & $1.8 \pm 0.2$ & $8.0 \pm 1.1$ & $2.1 \pm 0.6$ & $14.2 \pm 2$ \\
\hline Control & $4.6 \pm 0.4$ & $3.1 \pm 0.9$ & BLD & & $1.7 \pm 0.4$ & $17.6 \pm 2.3$ & $45.6 \pm 2.49$ & $87.4 \pm 4.0$ & $47.2 \pm 3.7$ & $207.2 \pm$ \\
\hline
\end{tabular}


Table 4

Quantification of some targeted compounds and antioxidant activities of the samples extracts.

\begin{tabular}{|c|c|c|c|}
\hline Plant sources & $\begin{array}{l}\text { Quantity of active compounds } \\
\text { (mg/g freeze-dried of crude extract) }\end{array}$ & DPPH\% & $\begin{array}{c}\text { FRAP } \\
\text { (mgQE/g freeze-dried of } \\
\text { sample extract) }\end{array}$ \\
\hline Turmeric & & $47.4 \pm 2.6$ & $55.8 \pm 0.4$ \\
\hline Curcumin & $280.1 \pm 0.3$ & & \\
\hline Desmethoxycurcumin & $81.1 \pm 0.1$ & & \\
\hline Bisdesmethoxycurcumin & $69.1 \pm 0.5$ & & \\
\hline Curry leaf & & $41.7 \pm 1.0$ & \\
\hline Rutin & $0.1 \pm 0.00$ & & \\
\hline Quercetin-3-glycoside & $5.4 \pm 0.0$ & & \\
\hline Myrecitin & 2. $4 \pm 0.0$ & & \\
\hline Quercetin & $0.1 \pm 0.0$ & & \\
\hline \multicolumn{2}{|l|}{ Torch ginger } & & \\
\hline Chlorogenic acid & $21.8 \pm 0.0$ & & \\
\hline Lemon grass & & & $8.4 \pm 0.9$ \\
\hline Caffeic acid & $0.1 \pm 0.0$ & & \\
\hline p-coumaric acid & $0.3 \pm 0.0$ & & \\
\hline luteolin-7-o-glycoside & $0.4 \pm 0.0$ & & \\
\hline
\end{tabular}


Table 5

Concentration of HCAs precursor in beef, turmeric, curry leaf, torch ginger and lemon grass

1: Fresh weight

2: Dried weight

3: Not detected

Precursor $(\mu \mathrm{mol} / \mathrm{g})$
Raw Material

Raw beef Turmeric

$\left(\mu \mathrm{mol} / \mathrm{g} \mathrm{fw}{ }^{1}\right) \quad\left(\mu \mathrm{mol} / \mathrm{g} \mathrm{dw}^{2}\right)$

Curry leaf

( $\mu \mathrm{mol} / \mathrm{g} \mathrm{dw})$

$4.9 \pm 0.6$

$30.2 \pm 1.0$

$3.0 \pm 0.4$

$\mathrm{ND}^{3}$

Glutamic Acid

Glutamine

Glycine

Histidine

Isoleucine

Leucine

Lysine

Methionine

Ornithin

Phenylalanine

Proline

Serine

Threonine

Tryptophan

Tyrosine

Valine

Total amino acids

Creatine Glucose
$0.1 \pm 0.0$

$1.1 \pm 0.2$

$4.7 \pm 0.9$

$1.5 \pm 0.2$

$0.4 \pm 0.1$

$0.8 \pm 0.1$

$1.6 \pm 0.3$

$1.0 \pm 0.1$

$0.7 \pm 0.2$

$1.3 \pm 0.2$

$0.7 \pm 0.1$

$0.5 \pm 0.1$

$1.4 \pm 0.3$

$0.9 \pm 0.2$

$0.6 \pm 0.2$

$0.3 \pm 0.1$

$1.4 \pm 0.2$

$25.9 \pm 4.4$

$33 \pm 3.6$

$14.4 \pm 2.5$
ND

ND

$0.4 \pm 0.1$

$0.4 \pm 0.1$

$1.4 \pm 0.5$

ND

ND

ND

$0.9 \pm 0.1$

$0.9 \pm 0.2$

$15.6 \pm 1.1$

$4.8 \pm 1.1$

$0.6 \pm 0.2$

$0.3 \pm 0.1$

$1.36 \pm 0.5$

$66.2 \pm 5.8$

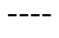

$405.1 \pm 6.1$

$1.4 \pm 0.4$

$3.5 \pm 0.9$

$0.8 \pm 0.2$

ND

$80.9 \pm 4.0$

ND

ND

$0.9 \pm 0.9$

$1.3 \pm 0.2$

$4.6 \pm 0.6$

ND

ND

$2.8 \pm 0.5$

$1.5 \pm 0.4$

$11.6 \pm 0.6$

$3.4 \pm 1.1$

$4.0 \pm 1.3$

$0.9 \pm 0.2$

$0.7 \pm 0.1$

$119.6 \pm 11.3$

$96.8 \pm 9.2$
Note:

Values display the mean values of $(\mu \mathrm{mol} / \mathrm{g} \mathrm{dw}) \longrightarrow$ triplicate determinat ions \pm SD

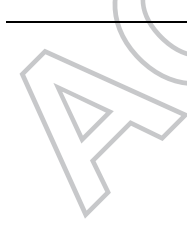


Table 6

Regression coefficients and $\mathrm{R}^{2}$ for the final reduced models (component proportions) of heterocyclic amines of grilled beef

\begin{tabular}{|c|c|c|c|c|c|c|c|c|}
\hline \multirow[t]{2}{*}{ Regression terms } & \multicolumn{3}{|c|}{ IQ } & \multicolumn{3}{|c|}{ PhIP } & \multicolumn{2}{|r|}{ Harmar } \\
\hline & Coefficient & F value & $P$ value & Coefficient & F value & $P$ value & Coefficient & F value \\
\hline X1 (Turmeric) & 0.025 & ---- & ---- & 0.18 & --- & ---- & 0.0 & --- \\
\hline X2 (Curry leaf) & 0.021 & ---- & ---- & 0.47 & -- & ---- & & --- \\
\hline X3 (Torch ginger) & 0.021 & ---- & ---- & 0.002 & 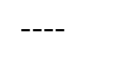 & -- & & ---- \\
\hline X4 (lemon grass) & 0.027 & ---- & ---- & 0.02 & ---- & & 0.10 & ---- \\
\hline X1X2 & 0.0003 & 19.08 & 0.001 & -0.009 & 25.43 & & & ---- \\
\hline $\mathbf{X 1 X 3}$ & ---- & ----- & ----- & ---- & & & & \\
\hline X1X4 & -1.83 & 5.2 & 0.04 & 0.009 & & 0.000 & -0.002 & 17.79 \\
\hline $\mathbf{X} 2 \times 3$ & ---- & ---- & ---- & ---- & & & -0.002 & 7.40 \\
\hline $\mathrm{X} 2 \mathrm{X} 4$ & ---- & ---- & ---- & 005 & & 0.014 & -0.003 & 12.32 \\
\hline X3X4 & ---- & ---- & ---- & & & ---- & ---- & ---- \\
\hline Regression & & 6.82 & 0.003 & & 17. & 0.000 & & 7.88 \\
\hline Linear & & 2.73 & 0.86 & & 34.17 & 0.000 & & 9.07 \\
\hline Quadratic & & 12.59 & 1 & & 15.58 & 0.000 & & 9.41 \\
\hline $\mathbf{R}^{2}$ & 72.39 & & & & & & 78.28 & \\
\hline
\end{tabular}

Table 6 (Continued)

Regression coefficients and $\mathrm{R}^{2}$ for the final reduced models (component proportions) of heterocyclic amines of grilled beef

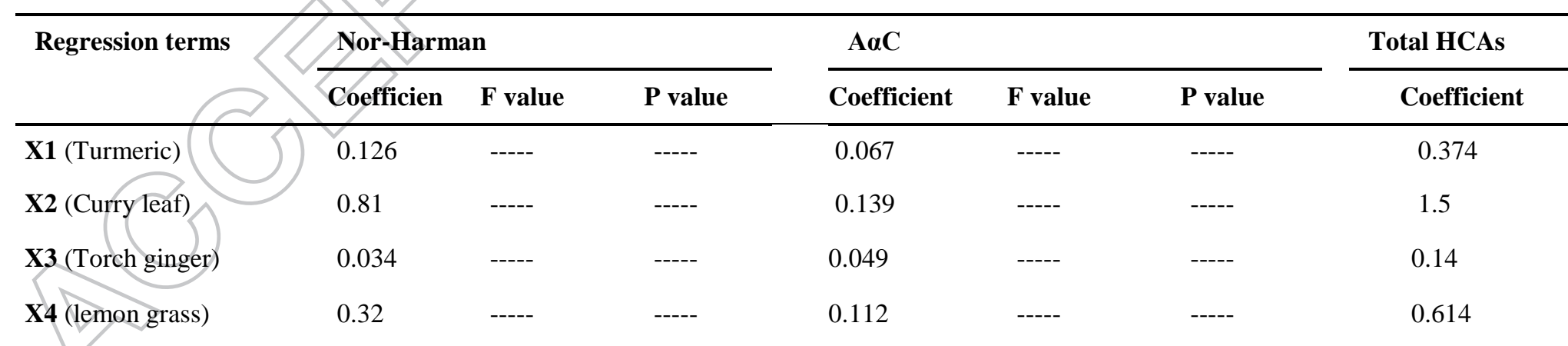


X1X2

\begin{tabular}{|c|c|c|c|c|c|c|c|}
\hline $\mathbf{X} 1 X 3$ & ---- & ----- & ----- & -0.001 & 6.27 & 0.031 & ---- \\
\hline X1X4 & -0.007 & 7.41 & 0.019 & -0.003 & 38.89 & 0.000 & -0.022 \\
\hline X2X3 & -0.007 & 7.81 & 0.016 & -0.002 & 18.27 & 0.002 & \\
\hline X2X4 & -0.01 & 13.20 & 0.003 & -0.003 & 40.65 & 0.000 & \\
\hline X3X4 & ---- & ---- & ---- & -0.001 & 9.58 & 0.011 & \\
\hline Regression & & 23.22 & 0.000 & & 19.72 & & \\
\hline Linear & & 39.30 & 0.000 & & 13.81 & & \\
\hline Quadratic & & 9.06 & 0.002 & & 20.66 & & \\
\hline $\mathbf{R}^{2}$ & 92.07 & & & 94.05 & & & 85.47 \\
\hline
\end{tabular}


Table 7

Effect of marinating on sensory attributes of grilled beef.

Samples Attributes

\begin{tabular}{|c|c|c|c|c|}
\hline & Colour & Tenderness & Flavour & Overall acceptability \\
\hline $\begin{array}{l}\text { Unmarinated grilled beef } \\
\text { (control) }\end{array}$ & 5.53 & 5.33 & 5.63 & 5.33 \\
\hline
\end{tabular}

*: Attributes with an asterisk indicate a significant difference from the control at $\mathrm{P}<0.05$

Table 8

Effect of optimized marinade formulation on mutagenicity measured by $S$. Typhimurium TA1535 and TA1538 in grilled beef

\begin{tabular}{lcc}
\hline Treatment & $\begin{array}{c}\text { S. Typhimurium TA1535 } \\
\text { revertants/g of grilled beef }\end{array}$ & $\begin{array}{c}S \text {. Typhimurium TA1537 } \\
\text { revertants/g of grilled beef }\end{array}$ \\
\hline $\mathrm{BaP}$ (positive control) & $109 \pm 20$ & $114 \pm 32$ \\
\hline Unmarinated grilled beef & $32 \pm 6^{*}$ & $48 \pm 8$ \\
Marinated grilled beef & $26 \pm 6^{*}$ \\
\hline
\end{tabular}

*: Attributes with an asterisk indicate a significant difference from the unmarinated sample at $\mathrm{P}<0.05$

Note: Values display the mean values of triplicate determinations \pm SD 


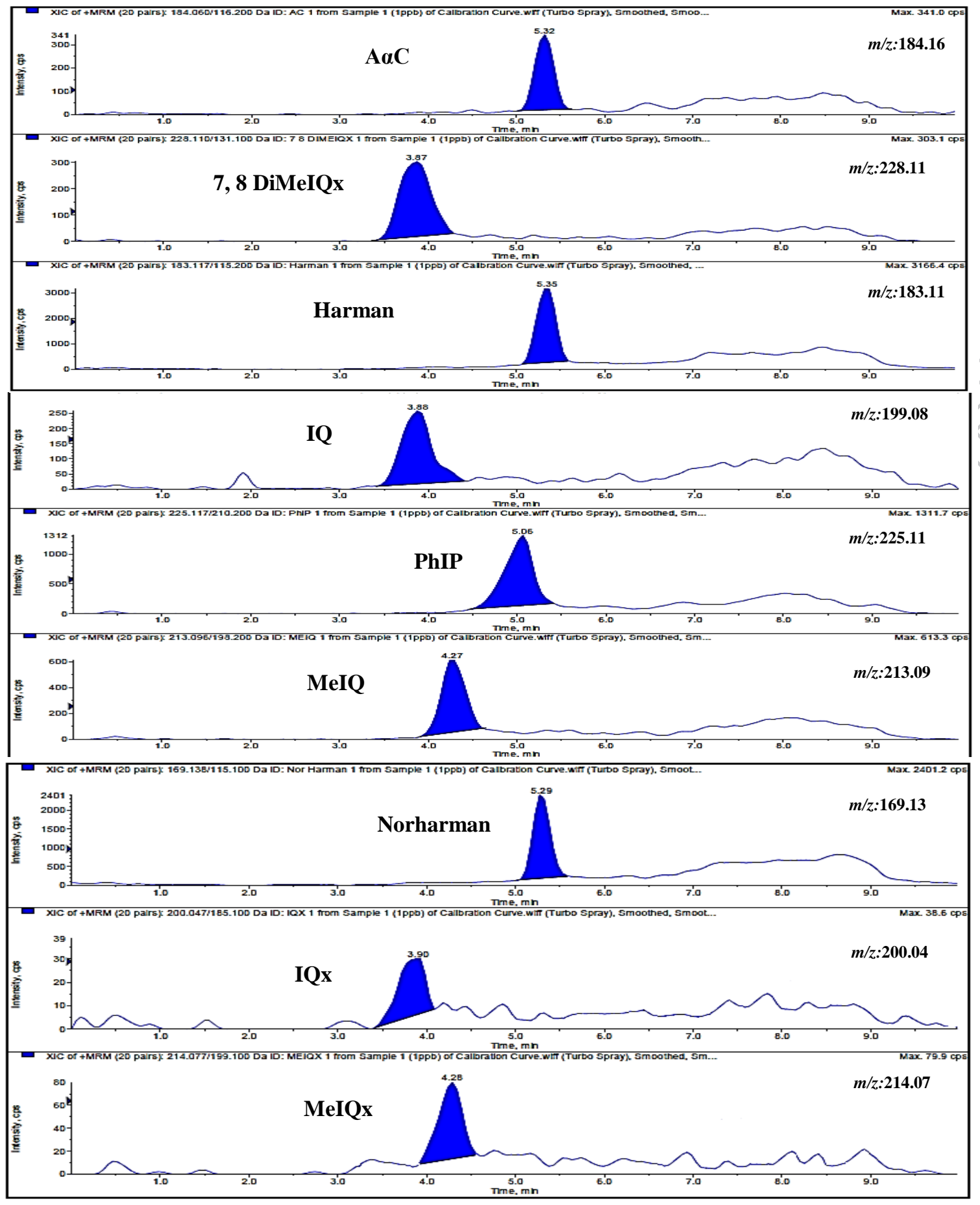

Fig. 1. Chromatograms of HCAs standard solution (1ppb) in MRM acquisition. 

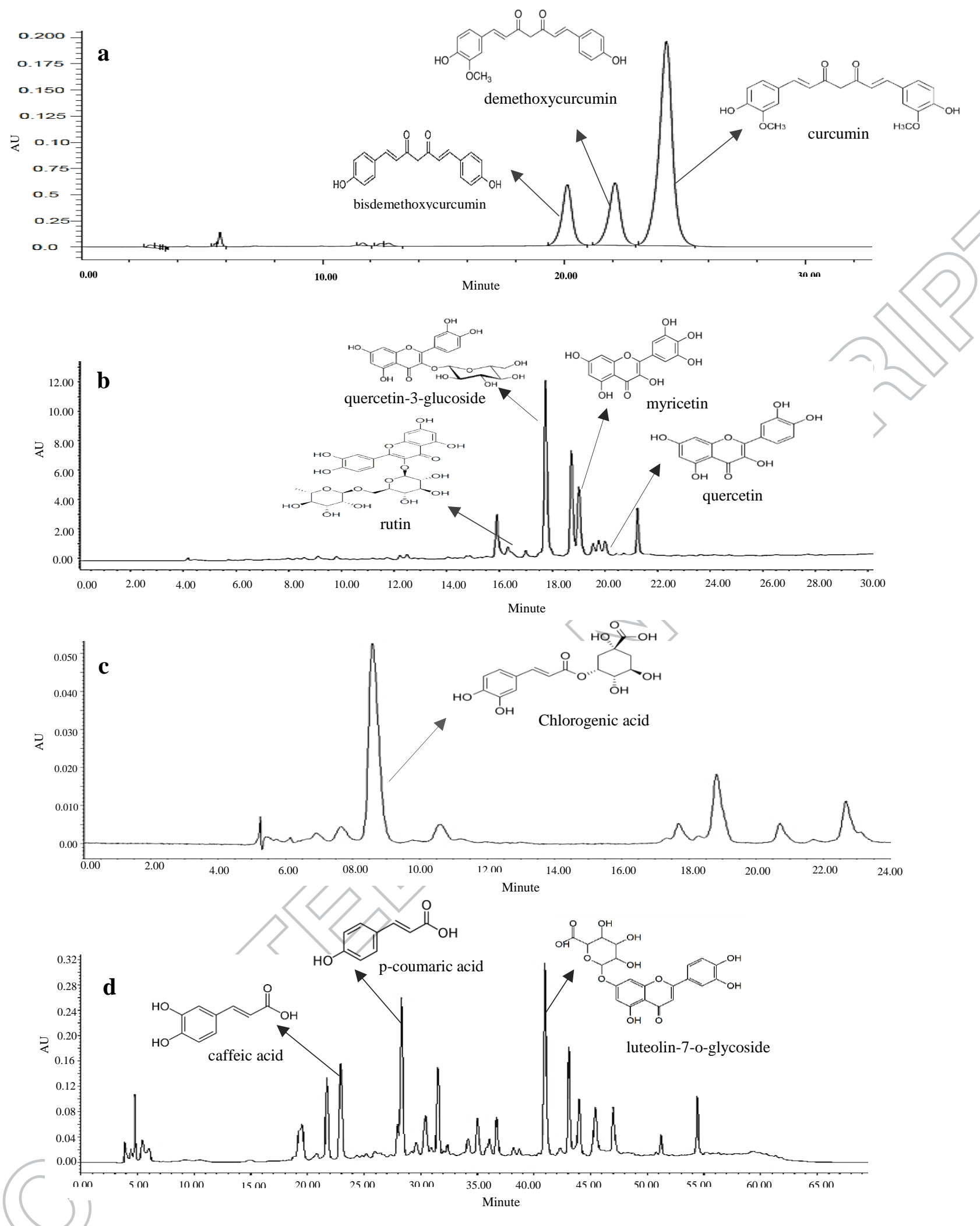

Fig. 2. HPLC profile of turmeric (a), curry leaf (b), torch ginger (c) and lemon grass (d). 

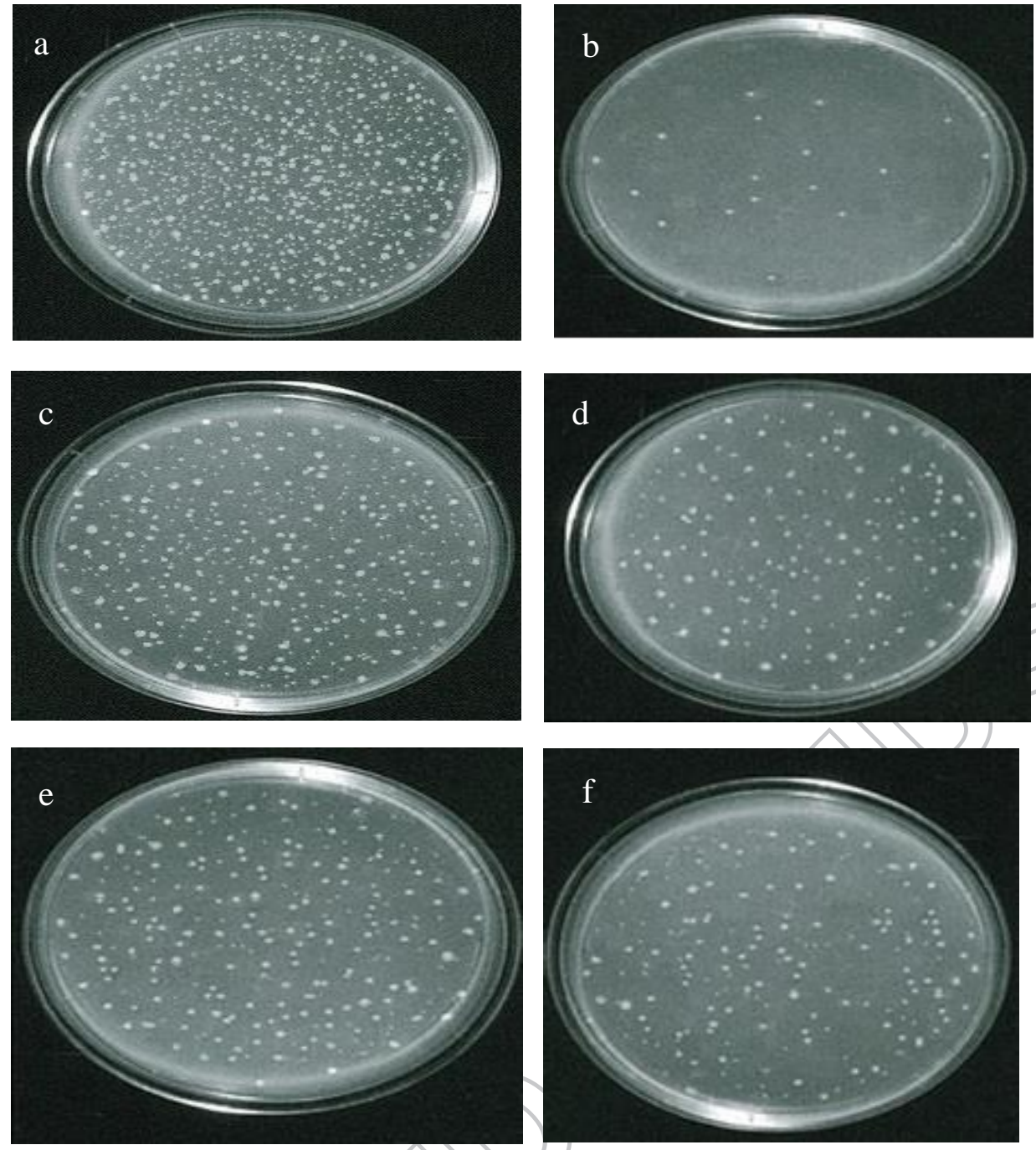

Fig. 3. Mutagenic activity of BaP as a positive control (a), 10\% DMSO as a negative control (b), unmarinated grill beef extract in $S$. Typhimurium TA1537 (c), marinated grill beef extract in $S$. Typhimurium TA1537 (d), unmarinated grill beef extract in $S$. Typhimurium TA1535 (e), marinated grill beef extract in $S$. Typhimurium TA1535 (f). 


\section{Graphical Abstract}

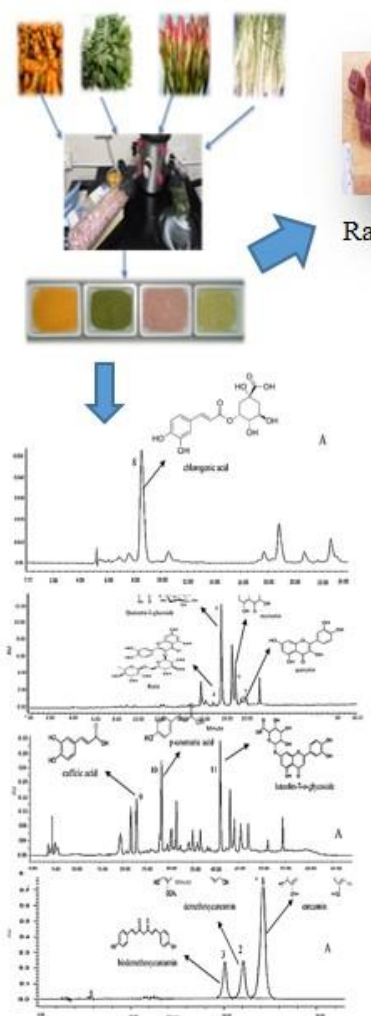

Phytochemicals of herbs/spices

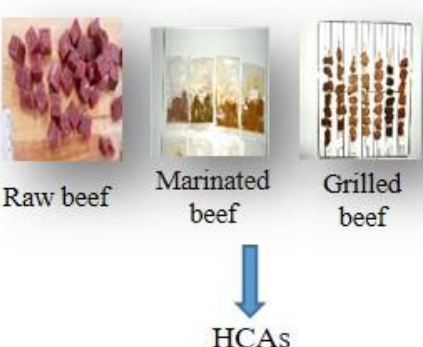

Analyzing

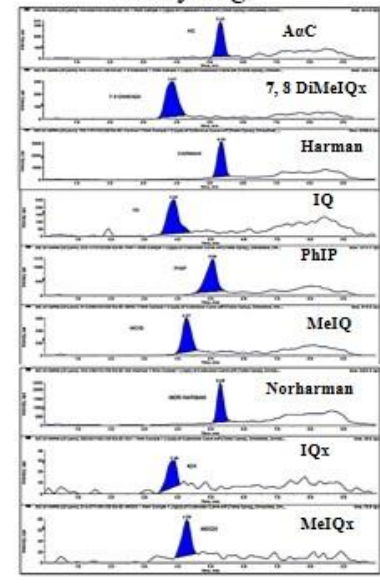

Evaluation of HCAs level in marinated grilled beef 